\title{
The Queer Materiality of History: H.D., Freud and the Bronze Athena
}

\author{
Jana Funke
}

\section{INTRODUCTION}

In February 1933, American-born writer H.D. (Hilda Doolittle) travelled to Vienna to be analysed by Sigmund Freud. H.D. entered into analysis for three months in 1933 and for five weeks in 1934. H.D. had a long-standing interest in psychoanalysis: she had begun to read psychoanalytic literature in the 1910s and had previously been analysed briefly by Mary Chadwick in London and Hanns Sachs in Berlin. ${ }^{1}$ In the early 1930s, she sought Freud's help to work through her writer's block and

\footnotetext{
'See Laura Marcus, "European Witness: Analysands Abroad in the 1920s and 1930s," in History and Psyche: Culture, Psychoanalysis and the Past, eds. Sally Alexander and Barbara Taylor (Basingstoke: Palgrave, 2012), 105-27.
}

The author gratefully acknowledges funding from the Wellcome Trust (NC106654/Z/14/Z and 106653/Z/14/Z).

J. Funke $(\square)$

University of Exeter, Exeter, UK

(C) The Author(s) 2019

J. Funke and J. Grove (eds.), Sculpture, Sexuality

and History, Genders and Sexualities in History, https://doi.org/10.1007/978-3-319-95840-8_10 
traumatic experiences during World War I, including the death of her brother and a miscarriage. The analysis also explored her bisexuality and her ambiguous gender identity. ${ }^{2}$

Knowledge of Freud's sessions with H.D. is one-sided: she wrote repeatedly about her analysis, but the psychoanalyst did not leave his own record. In the autumn of 1944, H.D. composed a retrospective essay called "Writing on the Wall", which was initially published in the journal Life and Letters To-Day (1945-1946). In 1948, she wrote a second piece, "Advent", which was allegedly taken from notebooks she had kept during her time in Vienna. "Writing on the Wall" and "Advent" were published together in a volume entitled Tribute to Frend in 1956. A third account is offered in H.D.'s poem "The Master", written before 1935 and published posthumously in $1981 .{ }^{4}$ Yet another perspective on the sessions can be found in the letters that H.D. wrote to her life-long partner Bryher (Annie Winifred Ellerman), who paid for the analysis, her lover Kenneth Macpherson and other members of her social circle. ${ }^{5}$

One widely noted aspect of H.D.'s conversations with Freud was their engagement with the psychoanalyst's precious and vast collection of Egyptian, Indian, Roman and Greek antiquities, which were displayed prominently in his office in Vienna. ${ }^{6}$ Both Freud's and H.D.'s imagination was captured by a specific object that would come to play an important role in the analytical sessions: a small bronze statue of Greek goddess Athena, which Freud kept on his desk and declared to be his

\footnotetext{
${ }^{2}$ For sustained accounts of H.D.'s encounter with Freud and engagement with psychoanalysis, see, for instance, Susan Stanford Friedman, Psyche Reborn: The Emergence of H.D. (Bloomington: Indiana University Press, 1981), 1-154; Dianne Chisholm, H.D.'s Freudian Poetics: Psychoanalysis in Translation (Ithaca: Cornell University Press, 1992); Cathy Gere, Knossos and the Prophets of Modernism (Chicago: Chicago University Press, 2009); and Valerie Rohy, "Exchanging Hours: A Dialogue on Time," GLQ: A Journal of Lesbian and Gay Studies 23, no. 2 (2017): 247-68.

${ }^{3}$ According to H.D., "Writing on the Wall" was written without recourse to notes, but "Advent" was taken directly from the notebooks of 1933. The notebooks are destroyed or lost.

${ }^{4}$ H.D., “The Master," Feminist Studies 7, no. 3 (1981): 407-16.

${ }^{5}$ This correspondence has been published as Analyzing Freud: Letters of H.D., Bryber and Their Circle, ed. Susan Stanford Friedman (New York: New Direction Books, 2002).

${ }^{6}$ For more on Freud as collector, see Richard H. Armstrong, Frend and the Ancient World: A Compulsion for Antiquity (Ithaca: Cornell University Press, 2005); Janine Burke, The Sphinx on the Table: Sigmund Freud's Art Collection and the Development of Psychoanalysis (New York: Walker \& Company, 2006).
} 
"favourite". 7 Measuring roughly $41 / 8$ inches, the statuette is a first- or second-century AD Roman copy of a Greek original from the fifth century BC. The figure holds a decorated libation bowl in the right hand. Her left arm is raised and her left hand would have held an object, presumably a spear or rod, which is now lost. ${ }^{8}$ The Bronze Athena, which Freud handed to and discussed with H.D. in their sessions, features in all of her accounts of the analysis. The statuette has also been central to critical debates about H.D.'s relationship with Freud with many scholars focusing on the tensions that arose due to the psychoanalyst's views of femininity and female sexuality: the statue's missing spear or rod has been interpreted as evidence of 'female castration', which Freud associated with penis envy and woman's physical lack of a phallus.?

While acknowledging these tensions, this chapter presents a different reading of H.D.'s engagement with the statuette and her relationship with Freud by focusing on the material and temporal qualities of bronze. Bronze took on a specific meaning in Tribute to Freud: in contrast to white marble, which was often linked to transcendence and abstraction in H.D's work, bronze came to be associated with more complex experiences of temporality and materiality. More specifically, bronze signalled an awareness of the losses of history and the difficulties of engaging with the past. Yet, the Bronze Athena also came to stand for the unexpected survival of the past in the present, signalling the potential to resist the passing of time. As such, in Tribute to Freud, bronze is associated with a range of temporalities that have recently been theorised as 'queer' in that they resist or at least complicate the "regular, linear and unidirectional qualities of 'straight time"', as Valerie Rohy states. ${ }^{10}$ These queer temporalities include an investment in historical loss, injury and damage as well as the anachronistic or untimely survival of the past in the present. In H.D.'s account, these queer temporalities are linked not only to her own bisexuality, but also to Freud's old age and his racialized Jewishness. Moreover, Tribute to Frend demonstrates that these queer temporalities are articulated through

${ }^{7}$ H.D., Tribute to Freud: Writing on the Wall and Advent (Manchester: Carcanet, 1985), 68.

${ }^{8} \mathrm{An}$ image and description of the statue can be found on the Freud Museum London website: https://www.freud.org.uk/collections.

${ }^{9}$ See, for instance, Rachel Blau DuPlessis and Susan Stanford Friedman, "Woman Is Perfect': H.D.'s Debate with Freud," Feminist Studies 7, no. 3 (1981): 417-30.

${ }^{10}$ Valerie Rohy, Anachronism and Its Others: Sexuality, Race, Temporality (New York: Suny Press, 2009), xiv. 
an engagement with nineteenth-century evolutionary science, which shaped both Freudian psychoanalysis and H.D.'s modernist aesthetics. ${ }^{11}$ Considering H.D.'s and Freud's encounter through this new framework challenges reductive readings of their relationship that have drawn too sharp a line between the allegedly divergent gendered and disciplinary affiliations of the male scientist and the female modernist poet. While H.D.'s engagement with the Bronze Athena does signal her resistance to Freud's understanding of female sexuality and femininity, the ancient object and the queer temporalities with which it is associated also cut across these divisions, thus facilitating dialogue between H.D. and Freud. ${ }^{12}$

\section{White Marble and Transcendence}

H.D.'s body of work, including poetry, novels, short stories and autobiographical writings, demonstrates an ongoing interest in sculpture. Her autobiographical novels-Paint It Today (composed in 1921), Asphodel (1921-1922) and HER (1926-1927) - are among the author's most overtly lesbian texts. ${ }^{13}$ In this trilogy, H.D. turns to marble statuary, especially of the Hellenistic period, to articulate the possibility of female homoeroticism. In Paint It Today, for instance, H.D.'s alter ego, Midget, encounters the classical marble statue of the Venus of Milo on a tour of the Louvre with her male partner, Basil. The imposing female statue holds out the possibility of transcendence from the realities of the museum space and allows Midget to distance herself from her heterosexual relationship with Basil. Gazing upon the marble statue, Midget experiences a homoerotic encounter that excludes Basil, who is incapable of understanding the "whitest passion" that connects the female observer with the sculpted female figure. ${ }^{14}$

\footnotetext{
${ }^{11}$ For more on the importance not to conflate queer temporality with non-normative genders and sexualities, see Ben Davies and Jana Funke, "Introduction," in Sex, Gender and Time in Fiction and Culture, eds. Ben Davies and Jana Funke (Basingstoke: Palgrave, 2011), 1-16.

${ }^{12}$ Due to the generic complexity and deliberate blurring of the autobiographical and fictional in H.D.'s work, the claims made in this chapter are not straightforwardly biographical. 'H.D.' and 'Freud' refer to historical figures, but also, primarily, to characters constructed in H.D.'s writings.

${ }^{13}$ All of these texts, like much of H.D.'s other prose fiction, were published posthumously.

${ }^{14}$ H.D., Paint It Today (New York: New York University Press, 1992), 60.
} 
H.D.'s female homoerotic use of marble statuary constitutes a significant appropriation of existing masculine traditions in art history and literature, and she refers explicitly to earlier female authors who had begun to subvert such male-oriented articulations of statuary for queer female purposes, especially Vernon Lee (Violet Paget). ${ }^{15}$ H.D. was aware of the romantic heterosexual tradition that had framed the Venus of Milo statue as an icon of female beauty for male heterosexual writers. ${ }^{16}$ In addition, as Cassandra Laity has shown, H.D. drew strategically on the finde-siècle movement of Decadence in which statuary had served to articulate male-male desire. ${ }^{17}$ In Paint It Today, H.D. describes Midget as a sister of Charmides, referring to Oscar Wilde's poem "Charmides" (1881) in which statue love comes to signal male homoeroticism. H.D. appropriates this male homoerotic tradition to express female same-sex desire. ${ }^{18}$

H.D.'s articulation of female homoerotic and androgynous possibilities through the encounter with marble statuary was also in direct dialogue with the work of late nineteenth-century art critic and literary scholar Walter Pater. As Eileen Gregory has argued, the language of 'whiteness' and 'white passion', seen in Midget's encounter with the Venus of Milo in Paint It Today, is directly related to Pater's association of whiteness with purity and transcendence. ${ }^{19}$ In The Renaissance: Studies in Art and Poetry (1873), Pater stated with regard to marble statuary: "That white light, purged from the angry, bloodlike stains of action and passion, reveals, not what is accidental in man, but the tranquil godship in him as opposed to the restless accidents of life". ${ }^{20}$ Here, marble whiteness indicates immortality and spirituality, the ability to transcend the material world and human body. Pater was indebted to earlier Romantic

${ }^{15}$ Paint It Today features a statuesque androgynous woman called Althea, a direct reference to Lee's novel Althea (1910). In this volume, see Ventrella for more on Lee, and Mechowski for a wider discussion of female homoerotic uses of statuary.

${ }^{16}$ Eileen Gregory, H.D. and Hellenism (Cambridge: Cambridge University Press, 1997), 96.

${ }^{17}$ Cassandra Laity, "H.D. and A.C. Swinburne: Decadence and Modernist Women's Writing," Feminist Studies 15, no. 3 (1989): 461-84.

${ }^{18}$ Cassandra Laity, "Introduction" to Paint It Today (New York: New York University Press, 1992), xxix.

${ }^{19}$ Gregory, Hellenism, 92-4.

${ }^{20}$ Walter Pater, The Renaissance: Studies in Art and Poetry (New York: Dover Publications, 2005), 139. For more on Pater and whiteness, see Richard Jenkyns, The Victorians and Ancient Greece (Cambridge: Harvard University Press, 1980), 146-9. 
and essentially Platonic associations of sculpture with abstraction and transcendent ideal beauty, as also found in the works of eighteenth-century art historian Johann Joachim Winckelmann, who had argued that sculptural art stood for "something beyond nature, namely certain ideal forms of its beauty". ${ }^{21}$ In this tradition, the white marble statue came to be associated with the transcendent leap out of the material world of sexual difference as represented by the sculpted figures of the androgynous boy or dually sexed individuals venerated by Winckelmann and his contemporaries. $^{22}$ H.D. reworked this tradition and associated the marble statue and its whiteness with a transcendent androgynous beauty that served to express both her bisexual desire for male and female partners as well as her own sense of gender duality or androgyny. Following on from Winckelmann and Pater, the relation to temporality that H.D. articulates through the focus on white marble is one of overcoming temporal restraints in a bid to reach for an androgynous wholeness and unity that transcends time altogether.

However, H.D.'s writings also register ambivalence regarding the Paterian vision of white marble. ${ }^{23}$ The promise of transcending sexual difference and temporality altogether leaves little room for the negotiation of different gendered and sexual positions or temporalities. In contrast to transcendent white marble, in Tribute to Freud, the bronze statuette of Athena foregrounds H.D.'s own as well as Freud's vulnerability to the passing of time, as this chapter argues. H.D. also uses the ancient object to suggest that it is her own as well as Freud's anachronistic relation to time that promises to open up a strategy of resistance to historical loss and allows for dialogue through a shared investment in the past. ${ }^{24}$

${ }^{21}$ Winckelmann cited in Gregory, Hellenism, 93.

${ }^{22}$ Gregory, Hellenism, 93. See also Catriona MacLeod, Embodying Ambiguity: Androgyny and Aesthetics from Winckelmann to Keller (Detroit: Wayne State University Press, 1998).

${ }^{23}$ Gregory, Hellenism, 95-6.

${ }^{24}$ The aim of this chapter is not to propose a strict division between marble and bronze or the temporalities associated with these materials. H.D. repeatedly wrote about bronze in poems like "The Charioteer" and "Red Roses for Bronze", her work on cinema published in Close Up, and essays on aesthetics, such as Notes on Thought and Vision. A thorough investigation of the different uses of bronze in these texts, and their relation to her equally complex engagement with marble, is beyond the scope of this chapter and warrants further investigation. 


\section{The Missing Spear: Bronze and the Losses of History}

Existing readings of Freud's and H.D.'s discussion of the Bronze Athena have often focused on the debate about the Oedipal conflict provoked by the statuette. Over the course of their sessions, Freud diagnosed H.D. with "a desire for union with [...] [her] mother". ${ }^{25}$ H.D. was seen to long for the phallic mother, who stands for the pre-Oedipal phase in early childhood development, the stage in which the girl has not yet realised that she lacks a phallus. As H.D. recounts in "Writing on the Wall", Freud stated that the statue of Athena was "perfect $[. .$.$] only she$ has lost her spear". ${ }^{26}$ This statement has been seen as indicative of Freud's focus on female castration and lack, here represented by Athena's missing spear. According to this reading, Freud's decision to engage H.D. in discussions about the Bronze Athena was an attempt to "intimidate" his patient, as Collecott suggests, ${ }^{27}$ by reminding her of her own lack as a woman and by insisting that the return to the pre-Oedipal mother, associated with female wholeness and autonomy, was impossible.

It is clear that H.D. and Freud held conflicting views on female sexuality and femininity, as all of her accounts of the analysis register a sense of discomfort with the psychoanalyst's insistence on female castration. ${ }^{28}$ This disagreement is articulated most explicitly in H.D.'s poem "The Master", which she refused to publish during her lifetime out of fear that it would taint her relationship with Freud. ${ }^{29}$ In this text, H.D. counters Freud's emphasis on women's lack by affirming that "woman is perfect". ${ }^{30}$ Some scholars, most prominently Susan Stanford Friedman and Rachel Blau DuPlessis, have interpreted this statement as

${ }^{25}$ H.D., Tribute, 44.

${ }^{26}$ Ibid., 69, her emphasis.

${ }^{27}$ Diana Collecott, H.D. and Sapphic Modernism (Cambridge: Cambridge University Press, 1999), 254.

${ }^{28}$ Although Marcus, "European Witness," 120-1, suggests that H.D. was not entirely opposed to the idea of female castration. Keenly aware of Freud's renewed interest in female sexuality and penis envy in the 1930s, H.D. believed that her case (as well as that of Bryher) might allow Freud to articulate a new understanding of castration anxiety in relation to female homosexuality and bisexuality.

${ }^{29}$ Ibid., 417.

${ }^{30}$ H.D., "The Master," 411, her emphasis. 
a triumphant form of feminist resistance to Freud. Others have complicated this approach, suggesting that H.D. was interested in articulating an understanding of the bisexual female subject as split and divided, constituted by the loss of an original state of wholeness and unity and faced with the reality of her "two loves separate", 31 as H.D. writes in the poem. ${ }^{32}$ However, these two readings are not mutually exclusive: H.D.'s work demonstrates both a persistent interest in the possibility of returning to the pre-Oedipal phallic mother as well as an awareness of the inevitable losses that occur over the course of individual development.

As a historical object, the Bronze Athena also drew attention to the losses that accrue over vast spans of historical time beyond the individual life course. Both Freud and H.D. were invested in nineteenth-century evolutionary frameworks that associated bisexuality with a primordial past that had been overcome through subsequent stages of evolutionary development. ${ }^{33}$ From the nineteenth century onwards, evolutionary sciences had created a strong association between primitive or primordial stages of development and bisexuality, understood here in the triple sense of physical sexual ambiguity, gender duality and sexual attraction to male and female partners. Charles Darwin, for instance, maintained that "some remote progenitor of the whole vertebrate kingdom appears to have been hermaphrodite [sic] or androgynous". ${ }^{34}$ Within this framework, the statuette of the warrior goddess without her phallic spear evoked the loss of an original state of bisexual wholeness associated not only with the early stages of individual development, but also with the primordial origins of the species and culture that had been overcome through subsequent evolutionary and historical developments.

The materiality of the Athena statuette, the fact that it was made of bronze rather than marble, raises awareness of the loss of the past due to historical change and progress. While some of the most famous marble statues, including the Venus of Milo discussed above, have also survived

${ }^{31}$ Ibid., 409.

${ }^{32}$ Claire Buck, H.D. and Freud: Bisexuality and a Feminine Discourse (Hertfordshire: Harvester Wheatsheaf, 1991), 72-99, pursues a Lacanian reading of the poem that puts emphasis on the split subject constituted in and through the language of sexual difference.

${ }^{33}$ Frank J. Sulloway, Freud: Biologist of the Mind (Cambridge: Harvard University Press, 1992), 158-60.

${ }^{34}$ Charles Darwin, The Descent of Man (London: Penguin, 2004), 189. 
in fragments, the materiality of bronze draws heightened attention to the workings of history and the passing of time. The colouration of bronze objects, the result of corrosion or patination, ${ }^{35}$ stands in contrast to the transcendent whiteness of marble that is prized within a Paterian framework. Compared to marble, bronze does not signal a leap out of time, but indicates a deep awareness of the materiality of the sculpted object and its vulnerability to historical processes of change. This is particularly true of Freud's Bronze Athena, which, as Janine Burke has highlighted, is "far from perfect $[\ldots]$. Her surface is pitted and scored. [...] She is small, plain and damaged". ${ }^{36}$ In a discussion of Freud's collection in "Writing on the Wall", H.D. highlights that "there are certain alloys [like bronze] [...] that may corrode and corrupt in time; and objects so blighted must be segregated or scrapped". ${ }^{37}$ This suggests that the passing of time can have such a damaging effect on artefacts made of bronze that the object might be beyond repair, suggesting the potentially irrecoverable loss of the past. ${ }^{38}$

The Bronze Athena clearly signalled to H.D. that this experience of loss was often gendered. Like other female modernist authors, H.D. was deeply aware of and concerned about the potential loss of women's history. As has been widely discussed, H.D. was fascinated with the Sapphic tradition and knew that the works of the female Greek poet had often survived only in fragments found in texts written by men. ${ }^{39}$ Freud and H.D. were both influenced by archaeologists like Arthur Evans and Jane Harrison, who suggested that early Greek societies, especially the pre-classical Minoan period of Cretan Knossos, had been matriarchal and had been replaced by later patriarchal cultures. ${ }^{40}$ Given H.D.'s profound interest in a matriarchal past that had been repressed by subsequent developments in patriarchal history, the loss of Athena's spear, a symbol of authority and power, signalled the fact that this past may no longer be accessible.

In H.D.'s imagination, the materiality of bronze acted as a reminder of the risk that women's history can be recast and replaced over the

${ }^{35}$ For a discussion of the particular material qualities of bronze objects, see Ittai Weinryb, The Bronze Object in the Middle Ages (Cambridge: Cambridge University Press, 2016), 1-16.

${ }^{36}$ Burke, Sphinx, 92, 97.

${ }^{37}$ H.D., Tribute, 41.

${ }^{38}$ See also Tim Martin, "From Cabinet to Couch: Freud's Clinical Use of Sculpture," British Journal of Psychotherapy 24, no. 2 (2008): 184-96, especially 189-90.

${ }^{39} \mathrm{See}$, for instance, Collecott, Sapphic, 78.

${ }^{40}$ Gere, Knossos, 77-80, 85-7. 
course of time. Bronze statues from Ancient Greece and Rome are much rarer than marble statues, because the metal was frequently melted and repurposed over the course of history due to its material value and relative scarcity. In H.D.'s writings on cinema from the late 1920s, bronze is often presented as a masculine and alienating material that is juxtaposed with a feminine marble. ${ }^{41}$ In her review of Carl Theodor Dreyer's historical film The Passion of Joan of Arc (1928), H.D. uses the term 'bronze' five times to convey her inability to access the film and relate to its protagonist, Jeanne, the "defiant bronze statue", envisioned here by a male director. ${ }^{42}$ H.D. describes the Medieval bronze relief decorating the doors of a church that fail to offer her entry and make her "very hands feel that they are numb and raw and bleeding, $[\ldots]$ beating at those very impregnable medieval church doors". ${ }^{43}$ Here, H.D. expresses her fear that the new cinematic portrait will replace and thereby put at risk her own image of the female saint. Just as the bronze church doors, associated with Medieval Christianity, might have been manufactured by melting earlier Greek or Roman sculptures, the film threatens to recast the image of the female saint in a way that excludes H.D. from a female historical tradition in which she is invested. Bronze-by virtue of its plasticity and ability to be moulded and recast in response to shifting values and ideals-draws attention to those aspects of the past that are at risk of being lost as history is written and rewritten by those in power.

For H.D., the awareness of the losses of history was not limited to the historical exclusion of women, however. The Athena was not the only damaged object owned by Freud. Looking around his office, H.D. might also have spotted another bronze artefact: a statuette of the male god Zeus that may have held a spear in his left hand, which is now lost. ${ }^{44}$ Moreover, the statuettes of Athena and Zeus owned by Freud

${ }^{41}$ See, for instance, H.D., "Borderline: A Pool Film with Paul Robeson," in Close Up: Cinema and Modernism, eds. James Donald, Anne Friedberg, and Laura Marcus (London: Continuum, 1998), 221-36, especially, 227-8.

${ }^{42}$ H.D., "Joan of Arc," in Close Up, 130-3; 131. H.D.'s "considerable ambivalence" towards the film has been noted by Marcus, Tenth Muse, 334. See also Susan McCabe, Cinematic Modernism: Modernist Poetry and Film (Cambridge: Cambridge University Press, 2005), 148.

${ }^{43}$ H.D., "Joan of Arc," 130.

${ }^{44}$ See Freud Museum London: https://www.freud.org.uk/collections. 
are reminiscent of some of the most famous damaged bronze statues depicting male characters. The Artemisian Zeus or Poseidon in the National Archaeological Museum of Athens, for instance, can no longer be identified unambiguously, because the trident or thunderbolt once held by the statue, symbols of Poseidon and Zeus respectively, is lost. In this regard, the Bronze Athena with her missing spear embodies a more general threat associated with the passing of time, which affects both H.D. and Freud. ${ }^{45}$ Indeed, H.D. stresses repeatedly that the male psychoanalyst, too, is at risk of being eliminated by historical change. She puts emphasis on Freud's advanced age and impending death; she also notes the coming of the Second World War and the rise of Nazi power that poses an immediate danger to the Jewish psychoanalyst. ${ }^{46}$ As Rohy has demonstrated in her sophisticated reading of "Writing on the Wall", H.D. associates historical time with the threatening move towards a future that will potentially annihilate both analyst and analysand: in H.D.'s text, "'history' names a temporality of unavoidable loss, whose effects cannot, perhaps, be forestalled, but with which one should never be complicit". ${ }^{47}$

Presenting H.D.'s and Freud's identity positions as different but analogous, Tribute to Freud suggests that analyst and analysand are able to forge a connection because they are both threatened by the passing of time. Aware of their precarious position, they share an attachment to the damaged and partially lost bronze artefact. Heather Love presents such "stubborn attachments to lost objects" as one expression of the queer impulse to 'feel backward', ${ }^{48}$ to dwell on and be vulnerable to moments of historical injury, failure and damage. Whereas Love focuses primarily on the "gender and sexual deviants" who have been eliminated (literally and figuratively) from Western history, ${ }^{49}$ Tribute to Freud works with a

\footnotetext{
${ }^{45}$ Buck, Bisexuality, 11, rightly points out that Freudian psychoanalysis was founded on failures of masculine claims to sufficiency and coherence, as the case studies of the Rat Man, the Wolf Man and Paul Schreber indicate.

${ }^{46}$ In Tribute to Freud, H.D. comments frequently on Freud's old age (for instance, 62 and 97) and describes the chalk swastikas painted on the street leading "to the Professor's door" (59). Similar comments are found in letters written in 1933 and 1934. For more on H.D.'s political awareness at the time of her analysis with Freud, see Marcus, "European Witness," 124.

${ }^{47}$ Rohy, "Exchanging," 252.

${ }^{48}$ Heather Love, Feeling Backward: Loss and the Politics of Queer History (Cambridge: Harvard University Press, 2007), 7.

${ }^{49}$ Love, Feeling Backward, 1.
} 
broader understanding of the queer experience of historical injury and loss: what is queer about H.D.'s and Freud's joint investment in the missing spear is the backward turn towards an at least partially lost past, a move that draws attention to H.D.'s and Freud's shared vulnerability. In this regard, relying on an antagonistic gendered reading of the missing spear as indicative of female castration alone overlooks important points of continuity between H.D. and Freud that are explicitly foregrounded in the text: the Bronze Athena represents the wider losses of history that affect Freud and H.D. in similar ways, albeit for different reasons.

\section{Anachronistic Survivals: The Bisexual Oracle and the Old Man of the Sea}

If the Bronze Athena embodies historical injury, it also stands for a mode of resistance to the passing of time: while damaged and scarred, the bronze object is an unusual, precious and rare remnant from the past, an unlikely survival. As such, it becomes central to H.D.'s search for ways of resisting and redressing historical loss, a project that connects her modernist aesthetics with psychoanalysis. ${ }^{50}$ To reach back to an otherwise lost past, both Freud and H.D. turned to nineteenth- and early twentieth-century scientific understandings of development, heredity and memory to cast themselves and each other in the role of anachronistic survivals, suggesting that they might have special abilities to access and retrieve the past.

The Athena statuette is not unique among Freud's antique objects in facilitating the attempt to reach back to the past, which is at the very heart of psychoanalysis. As is well-known, Freud presented psychoanalysis and archaeology as analogous, since both involved the search for the buried and forgotten treasures of the cultural and individual past. ${ }^{51}$ Most scholars of psychoanalysis read this relationship between the cultural past, represented by the antique objects, and the psychic past of the individual as metaphorical. ${ }^{52}$ However, Freud believed in a deeper link between the ancient objects and the individual's psyche. He arrived at this conclusion by building on German embryologist Ernst Häckel's

\footnotetext{
${ }^{50}$ See also Merril Cole, "Symptom or Inspiration? H.D., Freud, and the Question of Vision," Journal for Cultural and Religious Theory 10, no. 2 (2010): 83-98.

${ }^{51}$ See the introduction to this volume as well as the references in note 6 of this chapter.

${ }^{52}$ Armstrong, Antiquity, 41, argues against this misreading.
} 
recapitulation theory, which suggested that the development of the child (ontogeny) repeated the stages of evolutionary development of the species (phylogeny). ${ }^{53}$ This approach allowed Freud to maintain that the individual psyche contained elements of the deep cultural past. ${ }^{54} \mathrm{He}$ drew on the concept of organic, ancestral or 'race' memory to express the notion that individuals might have inherited memories of their ancestors, which can be recalled in the present. ${ }^{5}$ As Freud explained in "An Outline of Psycho-Analysis" (1938): "not a few of the child's new experiences will be intensified because they are repetitions of some primaeval phylogenetic experience" ${ }^{56}$ Freud's antique objects were not simply metaphorical tools that served to represent the workings of the mind; he believed that these ancient artefacts contained ideas and experiences that were already part of the individual psyche by virtue of organic or inherited memory.

Such ideas about recapitulation were central to H.D.'s conversations with Freud, especially regarding her bisexuality. In "Writing on the Wall", she credits the psychoanalyst for bringing "the past into the present with his the childhood of the individual is the childhood of the race - or is it the other way round? - the childhood of the race is the childhood of the individual. [...] [T] he traits and tendencies of obscure aboriginial tribes, as well as the shape and substance of the rituals of vanished civilizations, were still inherent in the human mind - the human psyche". ${ }^{57}$ The belief that the child had a closer connection to the archaic past was particularly important for H.D., since early twentieth-century sexual sciences, including psychoanalysis, had turned to the concept of arrested development-the notion that an individual might be 'stuck' on an early stage of childhood development - to explain a wide variety of gendered and sexual phenomena, including homosexuality and bisexuality. ${ }^{58}$

\footnotetext{
${ }^{53}$ See, for instance, Stephen Jay Gould, Ontogeny and Phylogeny (Cambridge: Harvard University Press, 1977).

${ }^{54}$ Sulloway, Biologist, 245.

${ }^{55}$ Laura Otis, Organic Memory: History and the Body in the Late Nineteenth and Early Twentieth Centuries (Lincoln: University of Nebraska Press, 1994).

${ }^{56}$ Sigmund Freud, "An Outline of Psycho-Analysis," in The Standard Edition of the Complete Psychological Works of Sigmund Freud, ed. and trans. James Strachey (London: Vintage, 2001), 23: 206-7.

${ }^{57}$ H.D., Tribute, 12-3.

${ }^{58}$ For more on arrested development in relation to sexuality, see Kathryn Bond Stockton, The Queer Child, or Growing Sideways in the Twentieth Century (Durham: Duke University Press, 2009); Rohy, Anachronism.
} 
During their analysis, Freud affirmed that H.D. was "that all-but extinct phenomena, the perfect bi-", as H.D. reported enthusiastically in a letter to Bryher written on 24 November $1934 .{ }^{59}$ As DuPlessis and Friedman highlight, Freud's diagnosis of H.D. as bisexual offered her "an identity more powerful than the one conventionally accorded women". ${ }^{60}$ However, this was not only because the bisexual woman was seen to combine masculine and feminine attributes, as DuPlessis and Friedman acknowledge, but also because she was linked to the figure of the child and therefore closer to the cultural past. H.D. herself explained this idea in another letter to Bryher in which she explicitly connects the notion of arrested development with the Greek past: "stuck at the earliest pre-OE [oedipal] stage, and 'back to the womb' seems to be my only solution. Hence islands, sea, Greek primitives and so on". ${ }^{61}$

Read within this context, Freud's decision to place the Bronze Athena in H.D.'s hands was not merely an opportunity to remind his analysand of the inevitability of women's castration and lack. It was also a test to see whether the ancient object would resonate with H.D. in a particular way given her greater proximity to the past. As Cathy Gere states, H.D. might have represented for Freud a fascinating specimen of the developmentally arrested bisexual woman who could prove his ideas about inherited or ancestral memory that would later be articulated in Moses and Monotheism (1939). ${ }^{62}$ H.D. herself speculated that this was one of the reasons why Freud engaged her in conversation about his antiquities: "Did he want to find out how I would react to certain ideas embodied in these little statues, or how deeply I felt the dynamic idea still implicit in spite of the fact that ages or aeons of time had flown over many of them?" 33

The possibility that her own bisexuality did not only implicate her in a narrative of lack and loss, but also enabled her to activate remote memories and enjoy a closer experience of the past was deeply satisfying for H.D. She held esoteric beliefs regarding her own divinatory powers and repeatedly recorded hallucinations or visions, which she read as indicative of prophetic talents that allowed her to reach back to the past. A number of hallucinatory experiences in the late 1910s and early 1920s affirmed

\footnotetext{
${ }^{59}$ H.D. et al., Analyzing Freud, 497.

${ }^{60}$ DuPlessis and Friedman, "Woman," 425.

${ }^{61}$ H.D. et al., Analyzing Freud, 132.

${ }^{62}$ Gere, Knossos, 170.

${ }^{63}$ H.D., Tribute, 68.
} 
H.D.'s belief that she was capable of accessing the past in this way. Arguably the most well-known of these was an incident that occurred on her trip to Corfu in 1920 during which she saw a series of mystic signs projected onto the wall of the hotel room she shared with Bryher. Both H.D. and Bryher maintained that these visions were proof of the author's ability to receive messages from the past. ${ }^{64}$

As the title "Writing on the Wall" indicates, this particular visionary experience was central to her analysis with Freud, yet H.D. offers conflicting accounts of the psychoanalyst's response to her visionary abilities. At times, she suggests that Freud interpreted her visions as a "dangerous tendency or symptom", ${ }^{65}$ a pathological sign of arrest and regression. Following H.D.'s lead, scholars have cast Freud in the role of a rational man of science and progress who dismisses H.D.'s longing for the regressive return to the matriarchal and pre-Oedipal past as irrational and unhealthy. ${ }^{66}$ Yet, H.D.'s occasional self-presentation as a time-travelling female oracle whose gifts are denied by the male scientist embodied by Freud also needs to be read as a self-mythologising strategy that reinforces misleading gendered antagonisms and inaccurate divisions between science and literature. ${ }^{67}$

Whereas H.D. records Freud's dismissal of her visionary abilities in Tribute to Freud, she also presents an alternative account in a letter to Bryher, written on 19 March 1933, in which she states that the psychoanalyst called her mystical hallucinations "half-normal $[\ldots]$ a poem sequence that was not written". ${ }^{68}$ This demonstrates the complex temporalities Freud came to represent in H.D.'s accounts: ${ }^{69}$ when encouraging H.D. to overcome her arrested development and "dangerous" attachment to the archaic past and the phallic mother, ${ }^{70}$ he reinforces a

${ }^{64}$ For a discussion of H.D.'s visionary experiences, see, for instance, Cole, "Vision".

${ }^{65}$ H.D., Tribute, 41.

${ }^{66}$ See DuPlessis and Friedman, "Woman"; Joanna Spiro, "Weighed in the Balance: H.D.'s Resistance to Freud in 'Writing on the Wall'," American Imago 58, no. 2 (2001): 596-621.

${ }^{67}$ For more on H.D.'s self-mythologizing in relation to Freud, see Gere, Knossos, especially 164-6.

${ }^{68}$ H.D. et al., Analyzing Freud, 115.

${ }^{69}$ Rohy, "Exchanging," 256, offers a different (though not incompatible) reading of this letter in which she contrasts the narrative and diachronic with the lyrical and synchronic, the expanded moment.

${ }^{70}$ H.D., Tribute, 41. 
linear developmental time that insists on moving on from the past and thus entails loss. H.D.'s letter to Bryher, however, signals that Freud was also able to appreciate the poetic and literary significance of H.D.'s vision. More than that, for Freud and many of his contemporaries, the concepts of recapitulation, arrested development and ancestral memory offered scientific explanations for these visionary experiences by opening up an understanding of time as also potentially regressive. While an evolutionary framework presented regression or backwardness as "halfnormal" at best, ${ }^{71}$ this scientific model nevertheless offered H.D. a means to associate her bisexuality with her visionary abilities, thus bringing together the scientific and the literary or poetic. Freud's embrace of these different temporalities is not only indicative of the psychoanalyst's ability to switch from a scientific to a literary register; it is also representative of the complex articulations of time found within nineteenth- and early twentieth-century scientific debates. ${ }^{72}$

Read against this background, the Bronze Athena stands for the possibility of the untimely and unlikely survival of the past in the present. Freud's decision to hand H.D. the statuette as part of their analysis affirms her identification with the anachronistic "perfect bi-" and her ability to access the past. ${ }^{73}$ However, the statuette's damage also complicates the celebratory engagement with anachronism, acting as a reminder of the inevitability of loss resulting from a linear time of progress and change that neither Freud nor H.D. could escape, as discussed previously. Indeed, as Rohy rightly argues, the very concept of anachronism, by delegating gendered, sexual, racial and ethnic others to the primitive past, is complicit with a straight and linear time of progress that, as has been shown, threatened to exclude both H.D. and Freud. ${ }^{74}$ The Bronze Athena embodies both of these intertwined temporalities.

${ }^{71}$ H.D. et al., Analyzing Freud, 115.

${ }^{72}$ This is not to suggest that Freud was unskeptical of occult tendencies or ambivalent about the attention that should be paid to phylogenetic elements in relation to individual experience, which was one of the key sources of conflict between Freud and C.G. Jung. For more, see Armstrong, Antiquity, 153-4.

${ }^{73}$ H.D. et al., Analyzing Freud, 497.

${ }^{74}$ Rohy, Anachronism, xv. 
H.D. also cast Freud in the role of an anachronistic survival who enjoyed and was able to grant privileged access to the past. Describing the analyst as "the Old Man of the Sea" and reminding readers of "the treasures he had salvaged from the sea-depth" ${ }^{75}$ H.D. suggests a link between Freud's old age and his collection of antiquities. The image of Freud retrieving objects from the sea speaks to the temporalities of bronze: many of the best-preserved bronze statues were rescued from the sea where conditions are more favourable for preservation of bronze than they are on land and the objects are not at risk of being melted and repurposed. ${ }^{76}$ This again draws attention to the vulnerability and rarity of bronze objects, which are subject to the passing of time. Freud's old age, which H.D. stresses repeatedly in all of her accounts, makes him vulnerable to the passing of time. Yet, in discovering and retrieving the bronze objects from the sea where they have survived, Freud's old age and associated wisdom and knowledge also enable him to establish a deep connection to the past, allowing him to redress at least some of the losses of history.

In H.D.'s imagination, Freud's association with the past was achieved not only through his age, his extensive collection of antiquities or the conceptual tools for recovering the past that he developed as part of the psychoanalytic project. She also maintained that it was his Jewish ancestry, "the Professor's racial, ancestral background", 77 that forged a deep connection with remote ages: "He has his family, the tradition of an unbroken family, reaching back through this old heart of the Roman Empire, further into the Holy Land". ${ }^{78}$ Through this racialisation of Freud's Jewishness, ${ }^{79}$ the psychoanalyst was tied to the archaic past. Ultimately, in H.D.'s eyes, he became "part and parcel of these [antique] treasures". ${ }^{80}$ Importantly, it was not just H.D. who imposed

${ }^{75}$ H.D., Tribute, 97.

${ }^{76}$ Carol C. Mattusch, The Victorious Youth (Los Angeles: Getty Museum Studies on Art, 1997), 3.

${ }^{77}$ H.D., Tribute, 42.

${ }^{78}$ Ibid., 97.

${ }^{79}$ For more on racialised Jewishness, see Sander Gilman, The Jew's Body (New York: Routledge, 1991). Rohy, Anachronism, x, describes how anachronism connects sexually and racially different subjects through the force of analogy.

${ }^{80}$ H.D., Tribute, 97. 
this racialised narrative onto Freud. The psychoanalyst himself told his colleague Sândor Ferenczi in 1922 that his study of antiquities provoked "strange secret yearnings - perhaps for my ancestral heritage" ${ }^{81}$ H.D.'s accounts also suggest that Freud encouraged the association between his person and his priceless antiquities in conversation with his analysand. ${ }^{82}$

This indicates that Freud and H.D. understood themselves and each other within gendered, sexualised, racialized and age-inflected frameworks in which bisexuality and racialized Jewishness as well as old age were associated with the distant past. The assumption that she shared the experience of being an anachronistic survival with Freud by virtue of analogy can be seen as an expression of H.D.'s broader (and often problematically uncritical) "identification with the different and dispersed", those individuals who had been displaced by the forces of history. ${ }^{83}$ This opens up a different reading of her exchange with Freud, especially around the Bronze Athena, since it demonstrates that the attempt to resist the losses of history by affirming a deep connection to the past was a shared one, facilitating dialogue between the ageing Jewish psychoanalyst and the female bisexual writer.

\section{The Value of Bronze and the Queer Touch of the Past}

The key scene in "Writing on the Wall" in which H.D. discusses the Athena statuette with Freud foregrounds the material qualities of the artefact, in particular, its material value as an object made of bronze.

${ }^{81}$ Freud quoted in Gay, Freud: A Life for Our Time (London: J.M. Dent, 1988), 172.

${ }^{82}$ See, for instance, H.D. et al., Analyzing Freud, 34.

${ }^{83}$ Susan Stanford Friedman, "Modernism of the Scattered Remmant: Race and Politics in the Development of H.D.'s Modernist Vision," in H.D.: Woman and Poet, ed. Michael King (Orono: National Poetry Foundation, 1986), 91-116; 116. Friedman's intervention focuses on H.D.'s engagement with race in relation to blackness and African-American identity. In this context, the association between bronze and racial difference was reinforced in H.D.'s writings after she was involved in the 1930 film Borderline, which featured black actor Paul Robeson in a leading role. The film eroticised Robeson's body in ways resonant with other primitivist appropriations of blackness. H.D. herself would present Robeson in the form of an eroticised bronze sculpture in the title poem of her $1931 \mathrm{col}-$ lection Red Roses for Bronze. For more on race and primitivism in Borderline, see Carolyn A. Kelley, "Aubrey Beardsley and H.D.'s 'Astrid': The Ghost and Mrs. Pugh of Decadent Aestheticism and Modernity,” Modernism/Modernity 15, no. 3 (2008): 447-75. 
Shortly after Freud has told H.D. that the Athena is perfect except for the missing spear, she pauses the narrative to reflect on the analyst's use of the adjective 'perfect':

[...] when he said, she is perfect, he meant not only that the little bronze statue was a perfect symbol, made in man's image (in woman's, as it happened), to be venerated as a projection of abstract thought, Pallas Athené, born without human or even without divine mother, sprung full-armed from the head of her father, our-father, Zeus, Theus, or God; he meant as well, this little piece of metal you hold in your hand (look at it) it is priceless really, it is perfect, a prize, a find of the best period of Greek art [...] [;] like a Jew he was assessing its worth; the blood of Abraham Isaac and Jacob ran in his veins. ${ }^{84}$

Several scholars have read these comments, which associate Freud's Jewishness with materialistic values, as anti-Semitic slights made in retaliation for his remarks about the Bronze Athena's lost spear. ${ }^{85}$ H.D. does express her concern that the psychoanalyst will find the statue (and women) to be lacking and challenges his treatment of the object as a 'good' rather than a 'god', a pun that constituted an ongoing joke between them. ${ }^{86}$ However, in "Writing on the Wall", this materialism, associated specifically with the value of bronze, also becomes the basis for a specific engagement with the past that not only foregrounds tensions, but also facilitates dialogue.

In the passage above, H.D. articulates the difference between a transcendental and Platonic reading of statuary-the Athene as "a projection of abstract thought" - 87 akin to Winckelmann and Pater on the one hand, as discussed previously, and a materially grounded reading of the statue as a particular object to be valued and prized for its individual qualities on the other. In "Writing on the Wall", this difference between the abstract and the material is reinforced through the juxtaposition of

${ }^{84}$ H.D., Tribute, 70, her emphasis.

${ }^{85}$ See, for instance, DuPlessis and Friedman, "Woman," 421-2; Spiro, "Resistance"; Ariela Freedman, "Gifts, Goods and God: H.D., Freud and Trauma," English Studies in Canada 29, no. 3-4 (2003): 184-99, especially 186-7. Similar anti-Semitic sentiments are found in H.D.'s letters, for instance, H.D. et al., Analyzing Freud, 332.

${ }^{86}$ Freedman, "Gifts".

${ }^{87}$ H.D., Tribute, 70. 
the bronze object with the ivory statuette of Vishnu, which Freud discusses with H.D. shortly before he turns to the Athena. The white artefact depicting the Hindu god Vishnu, who is associated with overcoming and transcending physical and material desire, ${ }^{88}$ is here dismissed by H.D. as a "cold abstraction". 89

This rejection is surprising, since H.D. and Freud were both invested in the idea that ancient objects represented abstract and timeless ideals and principles that could be applied universally and transhistorically. As several scholars have remarked, Freud began to collect antique objects at the same time as he was writing The Interpretation of Dreams (1900). ${ }^{90}$ In this work, Freud suggested that unconscious thoughts materialised in the form of dream contents and maintained that there might be a universal dream language that cut across cultures and historical periods and could be used to decipher the individual unconscious. Artefacts from the past were seen to embody abstract ideals that could offer important insights into this universal language. As Armstrong highlights, Freud's desire for archaeology was also a "yearning for a clear and distinct body of demonstrable evidence coupled with a decisive consensus of meaning". ${ }^{91}$ H.D., too, was fascinated with the notion of a universal and transhistorical or timeless language, which she, like Freud, compared to Egyptian hieroglyphics. ${ }^{92}$ In the late 1920s and early 1930s, H.D. would see cinema as a medium that could offer a new picture-language to reveal Platonic abstractions, an argument she developed through the explicit comparison with marble statuary. ${ }^{93}$

In her encounter with Freud, as represented in "Writing on the Wall", however, H.D. rejects the white perfection and abstraction of the ivory Vishnu statuette, stating her strong preference for the Bronze Athena. ${ }^{94}$ One reason for H.D.'s ambivalence towards abstraction in this context

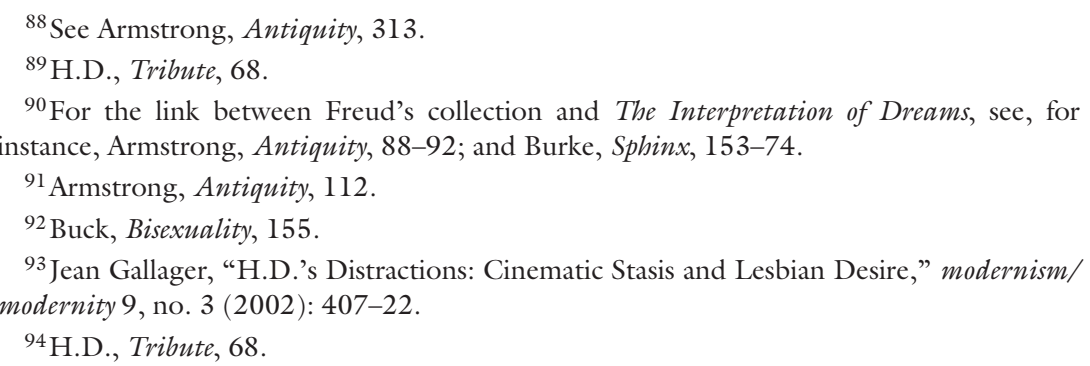


is that accepting the Athena as an abstract symbol might, within a Freudian framework, have meant accepting female castration as universal fact. Importantly, Freud was himself ambivalent about the feasibility of such universal readings. With regard to The Interpretation of Dreams, he contradicted his search for a universal language of dream symbols by acknowledging the "insuperable source of arbitrariness and uncertainty [that] arises from the fact that the dream-element may recall various things to the interpreter's mind and may recall something different to different interpreters". ${ }^{95}$ The same emphasis on indeterminacy is expressed when H.D. explains that "Freud says there are always a number of explanations for every finding, two or a multiple". ${ }^{96}$

In "Writing on the Wall", the indeterminacy and openness to different interpretations is closely connected with the specific materiality and temporality of bronze, which offers an alternative to the Paterian model of white marble that has been discussed earlier. This materialist engagement with the bronze object becomes possible, H.D. argues, because of Freud's "Jewish instinct for the particular in the general, for the personal in the impersonal or universal, for the material in the abstract". ${ }^{97}$ Without dismissing either H.D.'s discomfort with Freud's materialism or the anti-Semitic implications of her text, it is important to note that she also embraces a materialist approach that sees the Bronze Athena not as the abstract embodiment of universal ideals, but as a material object that can be valued and interpreted as an individual artefact with a specific history.

H.D. puts particular emphasis on the tactile nature of the exchange facilitated by her own and Freud's physical handling of the Bronze Athena, stating that the object constituted "something tangible, to be weighed and measured" by analyst and analysand. ${ }^{98}$ Handing the ancient object back and forth, a communicative exchange becomes possible between the male scientist and the female poet. One way of framing this encounter is

\footnotetext{
${ }^{95}$ Sigmund Freud, "The Interpretation of Dreams," in The Standard Edition of the Complete Psychological Works of Sigmund Freud, ed. and trans. James Strachey (London: Vintage, 2001), 4: 98, his emphasis.

${ }^{96}$ H.D., Tribute, 144. See also Rohy, "Exchanging," 256, and Cole, "Vision," 87, for a discussion of indeterminacy.

${ }^{97}$ H.D., Tribute, 71, her emphasis.

${ }^{98}$ Ibid., 70, her emphasis.
} 
to appropriate Carolyn Dinshaw's concept of the queer touch of the past, understood as a touch that does not deny differences between past and present or between different identity positions, but that facilitates "a queer historical impulse, an impulse towards making connections across time". 99 Whereas Dinshaw is interested in the ways in which individuals in the present can establish queer connections with different individuals in the past, H.D. explores the joint attempt on behalf of herself and Freud to communicate by touching the past through the Bronze Athena. The fact that both Freud and H.D. recognise each other-and the Bronze Athenaas anachronistic survivals is crucial in this context, since it opens up the past as a shared space to which both analyst and analysand have access and which they can jointly explore. Immediately after the exchange about the Bronze Athena, H.D. imagines herself climbing the steps to the Acropolis at Athens, which "[h]e [Freud] too had climbed [...] once". ${ }^{100}$ This shared memory of the temple of Athena is followed by a lengthy description of "universal consciousness" and the celebration of a language that was "the common property of the whole race". 101

If H.D. articulates the dream of a common language originating in the past, the Bronze Athena with her missing spear also draws attention to the losses of history, as explored previously; it suggests that a shared past is no longer easily accessible. What connects H.D. and Freud is not a shared understanding of the meaning of the lost spear, but an attachment and investment to the lost past that it represents. It is the very awareness of loss that makes possible Freud's and H.D's exchange by drawing attention to the inevitable indeterminacy of meaning: in its absence, the missing spear opens up a number of different interpretations. Instead of a universal language that can easily be shared and understood by all, trading the material object from one hand to the other and one moment in history to the next necessarily entails a loss of certainty that results from the different interpretative stances taken by individuals across time and across identity positions.

Instead of universal abstraction, timelessness and transcendence, bronze draws attention to the particularities of the individual object and

${ }^{99}$ Carolyn Dinshaw, Getting Medieval: Sexualities and Communities, Pre- and Postmodern (Durham: Duke University Press, 1999), 1.

${ }^{100}$ H.D., Tribute, 69.

${ }^{101}$ Ibid., 71. 
its relationship to history. The visible damage and age of the Bronze Athena shows that the object has not moved through time unharmed; on the contrary, it has changed its form and endured damage, and it bears the traces of its history. The fact that the statuette is a Roman copy of an earlier Greek original draws further attention to the fact that the past is always rearranged and represented in new ways by different interpreters in the present, thus resisting universalist and transcendental readings. ${ }^{102}$ In contrast to the ideal hieroglyphic language that holds out the promise of transhistorical understanding, or the transcendental whiteness of marble statuary that offers universal abstraction, the Bronze Athena opens up a different form of communication: foregrounding the impossibility of any singular or stable meaning, it facilitates an exchange that thrives on indeterminacy and openness of interpretation, thus allowing H.D. and Freud to connect while also leaving room for their divergent interpretations.

\section{CONCLUSION}

Instead of representing either the inevitable fact of female castration or the triumphant affirmation of female autonomy, Athena appears in H.D.'s accounts in the Greek goddess's traditional role as mediator and resolver of conflicts. Far from reinforcing gendered or disciplinary divisions between the male scientist and female literary author, the material qualities of the bronze statue were associated in H.D.'s imagination with articulations of temporality and modes of communication that resist universalising and transhistorical truths. In contrast to the abstract and transcendental qualities of white marble, the materiality of the Bronze Athena draws attention to experiences of temporality that, H.D. suggests, connect her and Freud: their shared resistance to the losses and injuries of history and their joint experience of anachronism, related to the former's bisexuality and modernist aesthetics and the latter's Jewishness and old age as well as his roles as founder of psychoanalysis and ardent collector of antiquities. As such, Tribute to Freud indicates that the statue of the Bronze Athena enabled H.D. and Freud to relate to each other through the queer touch of the past, establishing dialogue through a shared engagement with the past that acknowledges individual differences and thrives on the inevitable indeterminacies of meaning.

${ }^{102}$ See Burke, Sphinx, 94, for more on Freud's general dislike of forgeries and copies. 
Open Access This chapter is licensed under the terms of the Creative Commons Attribution 4.0 International License (http://creativecommons.org/licenses/ by $/ 4.0 /$ ), which permits use, sharing, adaptation, distribution and reproduction in any medium or format, as long as you give appropriate credit to the original author(s) and the source, provide a link to the Creative Commons license and indicate if changes were made.

The images or other third party material in this chapter are included in the chapter's Creative Commons license, unless indicated otherwise in a credit line to the material. If material is not included in the chapter's Creative Commons license and your intended use is not permitted by statutory regulation or exceeds the permitted use, you will need to obtain permission directly from the copyright holder.

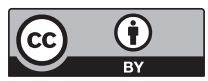

